\title{
Spectral characteristics and scatter cross-section of low latitude mesospheric echoes measured by the Indian MST radar at Gadanki
}

\author{
E. Belova ${ }^{1}$, S. Kirkwood ${ }^{1}$, T. Narayana Rao $^{2}$, S. Satheesh Kumar ${ }^{2}$, and T. Sergienko ${ }^{1}$ \\ ${ }^{1}$ Swedish Institute of Space Physics, Kiruna, Sweden \\ ${ }^{2}$ National Atmospheric Research Laboratory, Gadanki, India \\ Correspondence to: E. Belova (belova@irf.se)
}

Received: 20 December 2011 - Revised: 4 June 2012 - Accepted: 6 June 2012 - Published: 27 June 2012

\begin{abstract}
In November 2008 and in March and April 2009 the Indian MST radar $(53 \mathrm{MHz})$ at Gadanki was operated during the daytime in a special experiment, with $600 \mathrm{~m}$ altitude resolution, for understanding the characteristics of lowlatitude mesospheric echoes (LLME). The data of three days when the echoes were strongest have been analysed in terms of spectral widths and radar volume reflectivities. Spectral widths of LLME show some decrease with altitude, with median values of $4-6 \mathrm{~m} \mathrm{~s}^{-1}$ at $69-72 \mathrm{~km}$ and of $2-4 \mathrm{~m} \mathrm{~s}^{-1}$ at $73-78 \mathrm{~km}$. This corresponds to $20-200 \mathrm{~mW} \mathrm{~kg}^{-1}$ turbulent energy dissipation rates. It has been shown that stronger echoes have broader spectra consistent with a turbulent scattering mechanism. For the first time, the volume reflectivities for the strong LLME for Gadanki have also been calculated. They are in the range of $10^{-17}-10^{-15} \mathrm{~m}^{-1}$, so LLME at Gadanki are somewhat stronger than those reported so far from Jicamarca, Peru (Lehmacher et al., 2009).
\end{abstract}

Keywords. Meteorology and atmospheric dynamics (Middle atmosphere dynamics; Turbulence)

\section{Introduction}

Radar echoes from the mesosphere are a very common phenomenon observed by MST radars located over a wide range of latitudes, from the polar regions in both hemispheres to the tropics (e.g. Woodman and Guillen, 1974; Czechowsky et al., 1979; Ecklund and Balsley, 1981; Reid, 1990; Morris et al., 2004; Kirkwood et al., 2007; Smirnova et al., 2010). During the last three decades scientific interest has concentrated on strong radar returns from the mesopause region (80-90 km altitudes) observed in the summer months at polar latitudes, which have been termed polar mesosphere sum- mer echoes (PMSE). PMSE are due to fluctuations in radio refractive index caused by neutral turbulence in dusty plasma containing charged, nanometer-sized, ice particles. For a review on PMSE see e.g. Rapp and Lübken (2004). Summer mesosphere echoes at middle latitudes (MSE) show altitude and seasonal behavior similar to PMSE while their occurrence rate is much lower (Zecha et al., 2003; Bremer et al., 2006). It has been suggested that MSE are also related to the presence of ice particles either advected by the wind from the cold polar mesopause (Berger and von Zahn, 2007) or formed locally, e.g. during the cold phase of planetary waves (Zeller et al., 2009). At high latitudes another type of strongly enhanced radar return, different from PMSE, is sometimes found at altitudes below $80 \mathrm{~km}$, in the winter and equinox seasons. By analogy with PMSE these have been named polar mesosphere winter echoes (PMWE) (Kirkwood et al., 2002). The mechanism of PMWE generation is still unclear though both turbulent (Lübken et al., 2006) and nonturbulent (Kirkwood et al., 2006) hypotheses have been suggested.

At tropical latitudes mesospheric echoes are mostly weak and are observed all year round (e.g. Woodman and Guillen, 1974; Fukao et al., 1994; Kubo et al., 1997; Kumar et al., 2007). Recent studies of fine structure of low latitude mesospheric echoes, (which we will denote here by LLME) conducted using the $50 \mathrm{MHz}$ radar at Jicamarca, Peru, showed clear signatures of Kelvin-Helmholtz instability, due to strong wind shear (Lehmacher et al., 2007). LLME spectral widths have been used to estimate turbulent energy dissipation rates which were found to be in the range from 5 to $30 \mathrm{~mW} \mathrm{~kg}^{-1}$ (Guo et al., 2007).

The Indian MST radar at Gadanki $\left(13.5^{\circ} \mathrm{N}, 79.2^{\circ} \mathrm{E}\right)$ detects echoes from mesospheric altitudes during noon hours 
Table 1. The parameters of the Indian MST radar and experiment.

\begin{tabular}{llllll}
\hline $\begin{array}{l}\text { Geographic coordi- } \\
\text { nates }\end{array}$ & $\begin{array}{l}\text { Operating } \\
\text { frequency }\end{array}$ & $\begin{array}{l}\text { Transmitter peak } \\
\text { power }\end{array}$ & $\begin{array}{l}\text { Receive band } \\
\text { width }\end{array}$ & $\begin{array}{l}\text { Antenna 3-dB } \\
\text { beam width }\end{array}$ & $\begin{array}{l}\text { Antenna effective } \\
\text { area }\end{array}$ \\
\hline $\begin{array}{l}13.46^{\circ} \mathrm{N} 79.18^{\circ} \mathrm{E} \\
53 \mathrm{MHz}\end{array}$ & $2.5 \mathrm{MW}$ & $1.7 \mathrm{MHz}$ & $3^{\circ}$ & $10000 \mathrm{~m}^{2}$ \\
\hline $\begin{array}{l}\text { Pulse length (alti- } \\
\text { tude resolution) }\end{array}$ & $\begin{array}{l}\text { Pulse repetition } \\
\text { frequency }\end{array}$ & No. of bits in code & $\begin{array}{l}\text { No. of code permu- } \\
\text { tations }\end{array}$ & $\begin{array}{l}\text { No. of coherent in- } \\
\text { tegrations }\end{array}$ & Data resolution \\
\hline $600 \mathrm{~m}$ & $1000 \mathrm{~Hz}$ & 1 & 1 & 64 & $64 \mathrm{~ms}$ \\
\hline
\end{tabular}

(Rao et al., 2001). A climatological study by Kumar et al. (2007) has revealed the main characteristics of LLME in terms of occurrence, strength, altitude and seasonal dependencies. LLME are mostly located below $80 \mathrm{~km}$, and become stronger and more aspect sensitive in the winter and equinox seasons. However, the altitude resolution used in the climatology was as poor as $1.2 / 2.4 \mathrm{~km}$, and only signal-to-noise ratio (SNR) was used to compare strengths between different seasons. For accurate estimation of echo spectral widths in order to derive parameters of turbulence, one needs higher altitude resolution. For making comparisons with mesospheric echoes measured by other radars, some other characteristic of echo strength than SNR has to be used. The most appropriate is the volume reflectivity $\eta$, which is radar cross-section per unit volume. $\eta$ is defined by the absolute strength of the echo, i.e. by the scatterers themselves, with allowance made for the radar characteristics.

This paper is aimed at studying characteristics of LLME, in particular the spectral width and radar volume reflectivity, over Gadanki with high altitude resolution.

\section{Experimental settings}

The Indian MST $53 \mathrm{MHz}$ radar is located at Gadanki $\left(13.5^{\circ} \mathrm{N}, 79.2^{\circ} \mathrm{E}\right)$ in the south-eastern part of India. A description of the radar is given by Rao et al. (1995) and the main parameters are shown in Table 1. In November 2008 and in March and April 2009 the Indian MST radar was operated during the daytime in a special experiment for studying spectral characteristics of mesospheric echoes. An essential feature of this experiment was a high altitude resolution of $600 \mathrm{~m}$. (Additionally, we have tried 1-3 $\mu$ s pulse length providing $150-450 \mathrm{~m}$ altitude resolution, however the echoes were too weak for the derivation of the spectral parameters.) This altitude resolution allows us to detect fine structure of the mesospheric thin layers, which often contain a wave signature. Importantly, the spectra of the mesospheric echoes observed in this experiment would experience less shear broadening and broadening due to possible vertical wind variation over the altitude range, compared to previous LLME observations with the Gadanki radar, where the altitude resolution was $2.4 \mathrm{~km}$ (e.g. Kumar et al., 2007; Chandra et al., 2008). Thus, such experimental arrangements allow for the elimination of non-turbulent contributions to the spectral width and, finally, correct evaluation of the parameters of turbulence.

\section{Data analysis}

LLME were detected on several occasions, however, here we will concentrate on three days: 23 November 2008, 28 March and 11 April 2009, when mesospheric layers were particularly strong and long-lived. The details of these experiments are presented in Table 1.

For the estimation of spectral widths and Doppler velocities, at the altitudes where strong layers were detected by the radar, we firstly calculated a time series of the echo power with coherent integration over $64 \mathrm{~ms}$ and then used a 64 point FFT to get power spectra every $4.1 \mathrm{~s}$. (We have also tried other combinations of different coherent integrations and lengths of time series and found that this one gives less noisy spectra.) Then we subtracted the sky noise spectra, which were calculated for the "echoes" detected in the altitude range of 50-60 km and then averaged over these altitudes. Because the LLME signal was weak, the spectra were very noisy. Therefore, we followed a procedure described by Sheth et al. (2006). We fitted a generalized-Gaussian model (Eq. 4 ibid) to the experimental spectra and then used the "moments" method for estimation of spectral width and Doppler velocity, i.e. the second and the first moments of the power density model spectrum, respectively. Finally, we integrated spectral parameters over 8 samples to obtain spectral estimates, one each for $32.8 \mathrm{~s}$.

In order to calculate the volume reflectivity of LLME, the radar has to be calibrated (e.g. Kirkwood et al., 2007; Swarnalingam et al., 2009). Calibration of the Indian MST radar receive path was accomplished using the daily variation of galactic noise and direct signal injection tests in January 2010 (Kirkwood et al., 2010). For the transmit path we assume $50 \%$ losses in the antenna. The uncertainty in volume reflectivities primarily depends on the uncertainty in calibrating the receive path due to short duration of the experiments (Kirkwood et al., 2010). The total uncertainty is about a factor 2 for these experiments for the Gadanki radar, i.e. the real values maybe between half and twice those quoted. Then we were able to calculate LLME radar volume reflectivities 

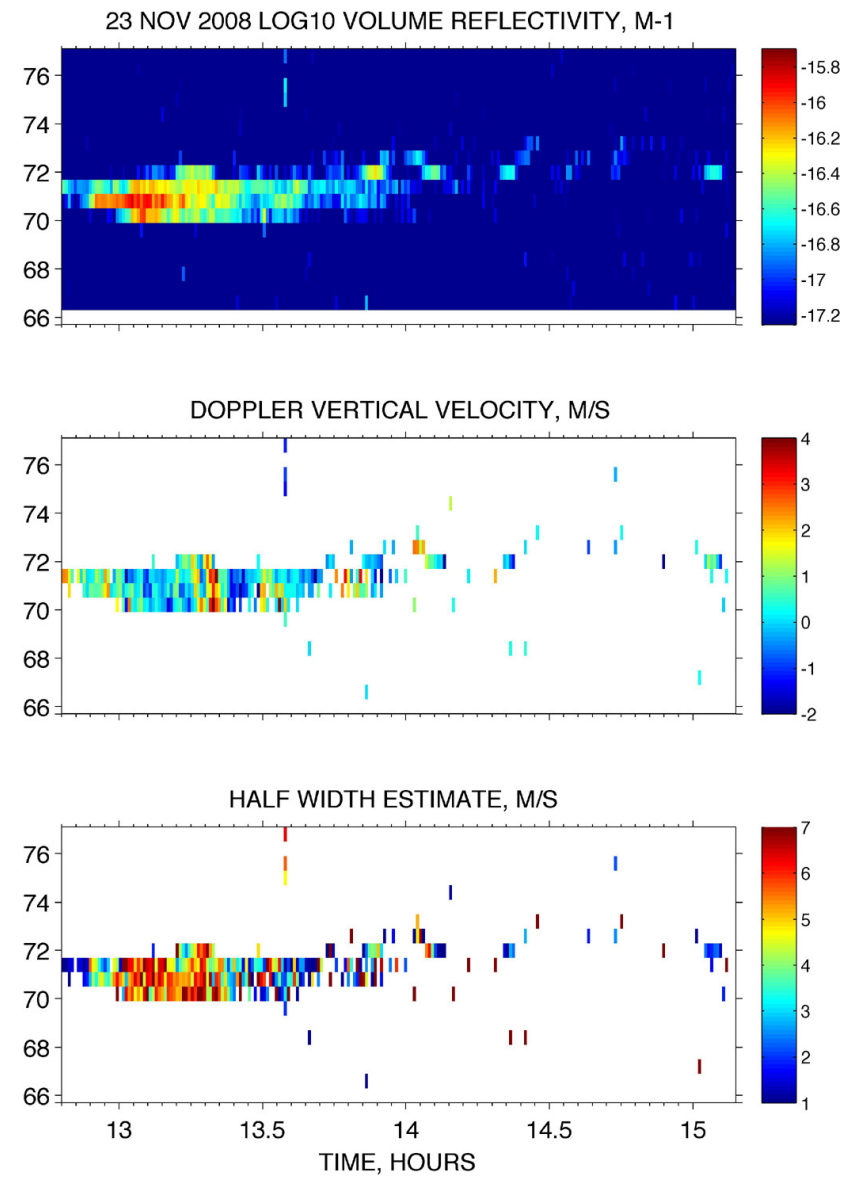

Fig. 1. $\log _{10}$ of radar volume reflectivity (upper panel), Doppler vertical velocity (middle panel) and half spectral width (lower panel) for the experiment on 23 November 2008. The vertical axis is altitude in $\mathrm{km}$.

using the same method as described for PMWE by Stebel et al. (2004) and applied for PMSE in Antarctica and the Arctic by Kirkwood et al. (2007).

\section{Experimental results}

On 23 November 2008 from about 10:00 LT to 15:10 LT, we ran a vertical beam experiment and a narrow layer of enhanced backscatter was detected during the whole experiment. However, the strongest echo appeared after about 12:50LT. Altitude profiles of echo volume reflectivity, Doppler velocity and spectral width (from this point and further the spectral width means the half-power half-width of the power spectrum of the signal) are presented in Fig. 1. We see a single layer with a thickness of $2.5 \mathrm{~km}$ with its peak at about $71 \mathrm{~km}$ altitude. It was strongest and thickest at 13:15 LT, subsequently becoming weaker and intermittent, and finally disappearing by 15:06 LT. The maximum of echo volume reflectivity was calculated to be $2 \times 10^{-16} \mathrm{~m}^{-1}$. Estimates of spectral width shown on the lower panel of Fig. 1
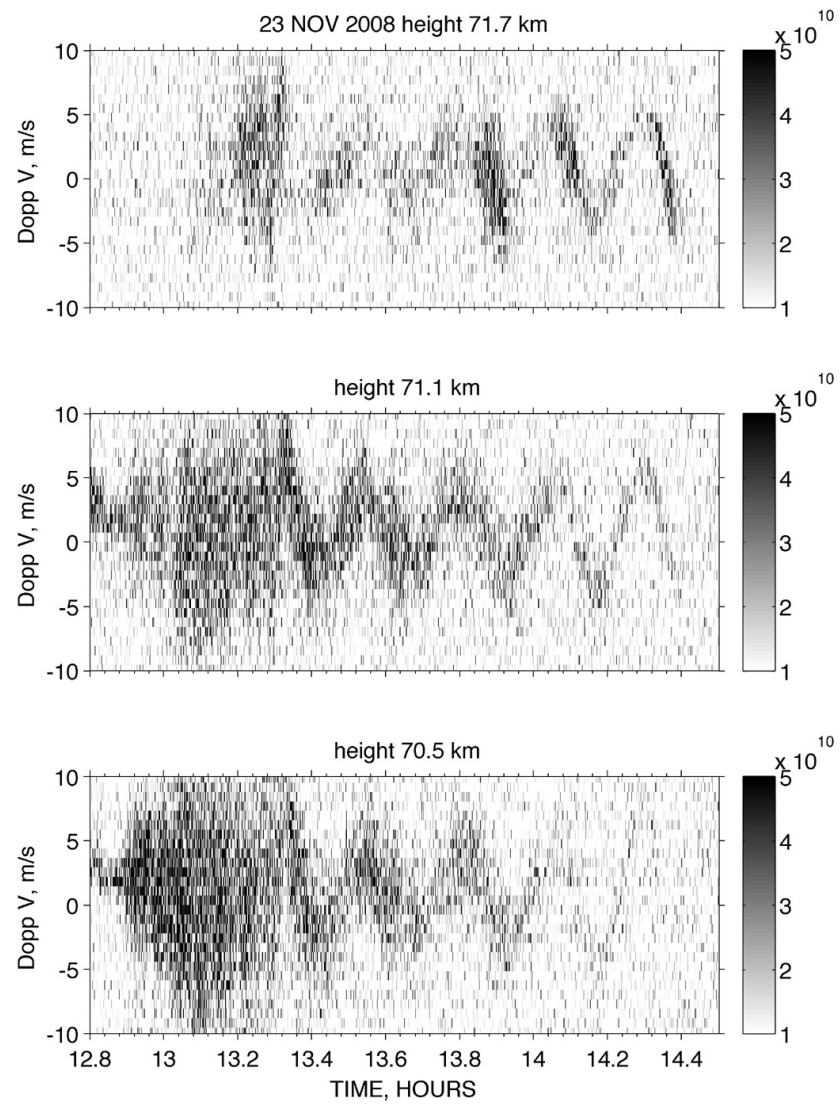

Fig. 2. Dynamical spectra of backscattered power with $4.1 \mathrm{~s}$ time resolution at three altitudes $70.5 \mathrm{~km}, 71.1 \mathrm{~km}$ and $71.7 \mathrm{~km}$ for the experiment on 23 November 2008. The gray scale represents power spectral density of the echo expressed in arbitrary units.

vary from $2 \mathrm{~m} \mathrm{~s}^{-1}$ to $7 \mathrm{~m} \mathrm{~s}^{-1}$. Doppler velocities in the middle panel show quite strong oscillations with a period of $\sim 15 \mathrm{~min}$. This may be a signature of a gravity wave with a wave vector which is close to horizontal. More clearly, these periodic variations are seen in dynamical spectra calculated for the three heights where the echo was strongest (Fig. 2). They start at about 13:20 LT and remain visible, at least at one height, until the end of the radar observations. There is no significant wave phase difference over $1.2 \mathrm{~km}$ altitude range which implies a vertical wavelength longer than $12-15 \mathrm{~km}$.

On 28 March 2009 we ran a two beam experiment switching between vertical and tilted ( $3^{\circ}$ north) beams every $37 \mathrm{~s}$. In Fig. 3 the altitude profiles of backscattered power for both beams and the ratio of the vertical to tilted beam power are presented. Here strong LLME are seen again as a single thin (mostly of $600 \mathrm{~m}$ thickness) layer at $\sim 76.5 \mathrm{~km}$ altitude from 16:00 LT until 16:35 LT. From this figure one can conclude that, despite difference in echo spatial and temporal variations between two beams, for most time the ratio is close to 1 , implying a low aspect sensitivity of the echoes. Dopplerderived meridional velocity, vertical velocity and spectral width are shown in Fig. 4. There is no signature of wave 

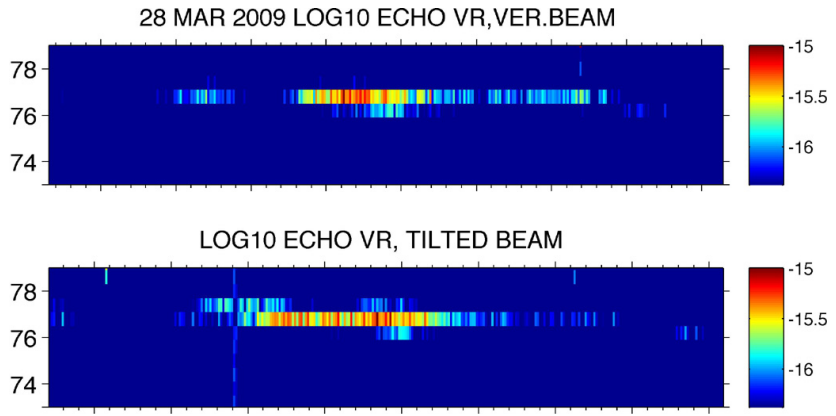

LOG10 VERTCAL TO TILTED VR RATIO

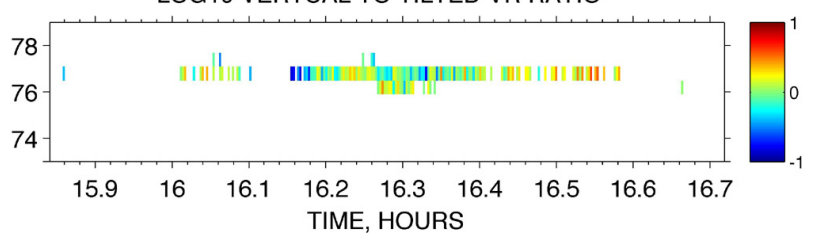

Fig. 3. $\log _{10}$ of radar volume reflectivity for the vertical (upper panel) and tilted (middle panel) beam and their ratio (lower panel) with time resolution of $4.1 \mathrm{~s}$ for the experiment on 28 March 2009. The vertical axis is altitude in $\mathrm{km}$.

modulation of the layer. Vertical velocities are found to be weak $\left(<0.5 \mathrm{~m} \mathrm{~s}^{-1}\right)$ and meridional velocities are moderate $\left(20-30 \mathrm{~m} \mathrm{~s}^{-1}\right)$. Spectral widths were derived for the vertical beam only, because spectral width for a tilted beam has to be additionally corrected for shear broadening due to horizontal winds. Spectral widths are about $1-5 \mathrm{~m} \mathrm{~s}^{-1}$. LLME strength was high, reaching a maximum volume reflectivity value of $10^{-15} \mathrm{~m}^{-1}$.

On 11 April 2009 we ran the same experiment as on 28 March, making observations with two radar beams. In Figs. 5 and 6 the results are presented in the same way as for the previous experiment. Figure 5, showing the altitude profiles of backscattered power, reveals multiple layers of LLME from 10:00 LT up to 12:30 LT. Echoes observed with the vertical and tilted beams show very similar spatial and temporal behaviour and low aspect sensitivity. The two most long-lived layers were located at $\sim 69.5 \mathrm{~km}$ and at $\sim 76.5 \mathrm{~km}$. The lower layer demonstrates a modulation by a wave with $15 \mathrm{~min}$ period which is clearer in the dynamical spectra (not shown). Vertical velocity is up to $2 \mathrm{~m} \mathrm{~s}^{-1}$, and meridional velocity reaches as high a value as $60 \mathrm{~m} \mathrm{~s}^{-1}$ (Fig. 6). Spectral widths are $1-5 \mathrm{~m} \mathrm{~s}^{-1}$. Maximum volume reflectivity for the upper layer is estimated to be $3 \times 10^{-16} \mathrm{~m}^{-1}$.

For every experiment we also calculated correlation coefficients between the echo strength and spectral width at each altitude where LLME were detected. The majority of the correlation coefficients are positive, however, their values and statistical significance vary a lot from case to case. In Fig. 7 three examples of positive correlation between echo volume reflectivity and spectral width with the highest statistical significance levels, one for each experiment, are presented as
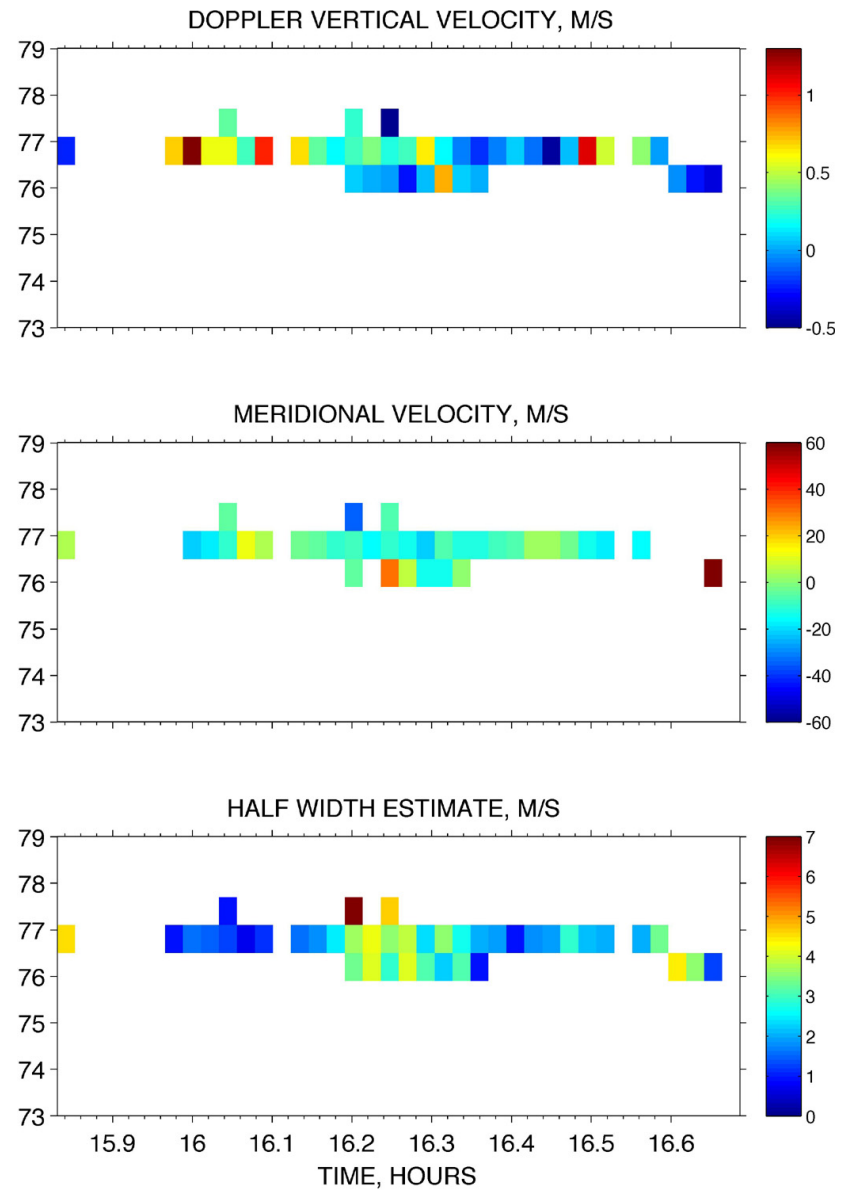

Fig. 4. Doppler vertical (upper panel) and meridional (middle panel) velocity and half spectral width for the vertical beam (lower panel) for the experiment on 28 March 2009. The vertical axis is altitude in $\mathrm{km}$.

scatter plots. There the correlation coefficients and probability values of getting correlation by pure chance were calculated using the MATLAB corrcoef function.

\section{Spectral width correction for beam broadening}

We presented the results of the calculations of spectral widths of LLME power spectra for three experiments in Figs. 1, 4 and 6 . We found the signatures of gravity waves with periods 10-20 min in LLME for two cases. The presence of such long period waves cannot affect spectra calculated with $4.1 \mathrm{~s}$ integration time. However, spectral widths should be corrected for additional beam broadening. According to Hocking (1985), the spectral width $w$ is related to the measured spectral width $w_{\mathrm{m}}$ and beam broadening $w_{\text {beam }}$ by

$w=\sqrt{\left(w_{\mathrm{m}}^{2}-w_{\text {beam }}^{2}\right)}$, 

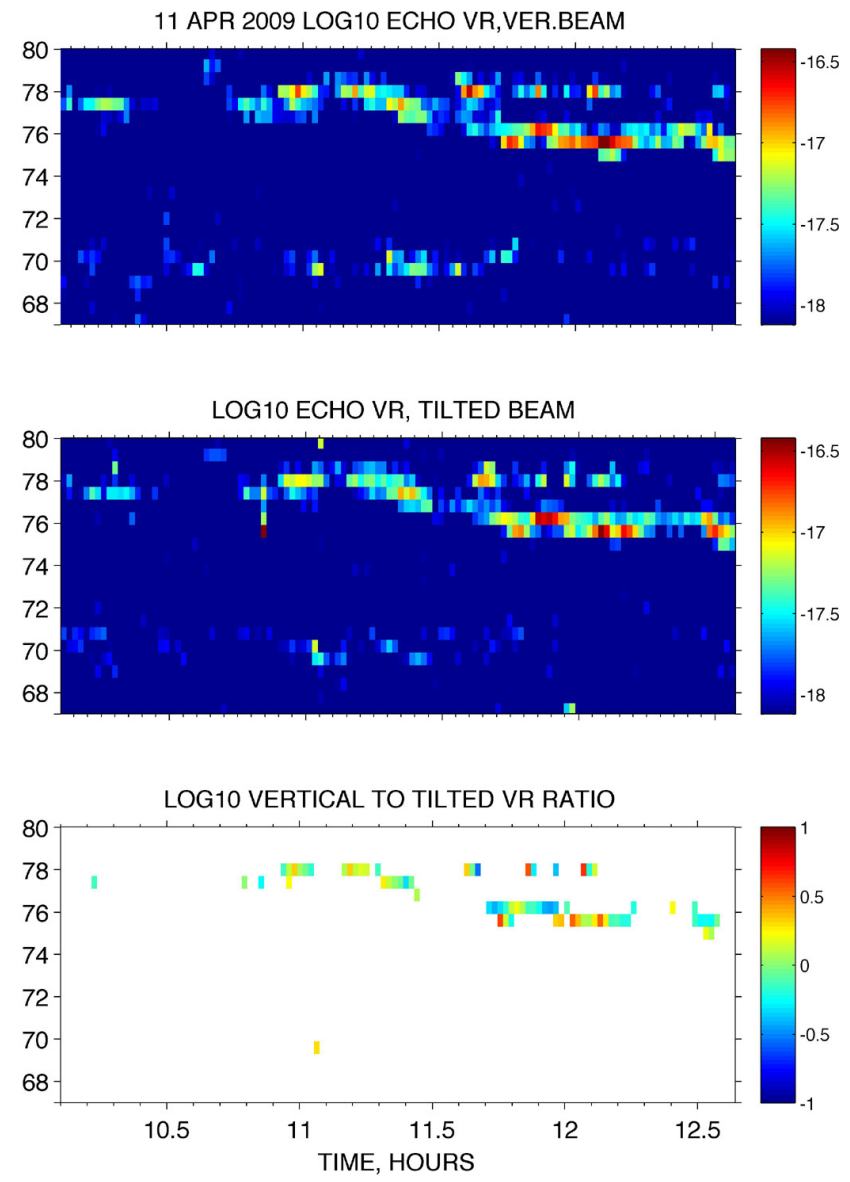

Fig. 5. $\log _{10}$ of radar volume reflectivity for the vertical (upper panel) and tilted (middle panel) beam and their ratio (lower panel) for the experiment on 11 April 2009. The vertical axis is altitude in $\mathrm{km}$.

where beam broadening $w_{\text {beam }}$ can be written as

$w_{\text {beam }}\left(m s^{-1}\right)=\theta_{1 / 2} \cdot V_{\text {hor }}=\frac{1}{2 \sqrt{2}} \cdot \theta \cdot V_{\mathrm{hor}} \approx 0.35 \cdot \theta \cdot V_{\mathrm{hor}}$,

where $\theta_{1 / 2}$ is the half-power half-width of the effective (2way) radar beam, $\theta$ is the $3 \mathrm{~dB}$ full beam width for transmission (or receiving), both in radians, and $V_{\text {hor }}$ is the horizontal wind speed.

In the experiment on 28 November 2008 the horizontal wind was not measured, however, from the experiment on 11 April 2009 the meridional component was found to reach up to $60 \mathrm{~m} \mathrm{~s}^{-1}$ (Fig. 6). That is in line with the study by Kishore Kumar et al. (2008), where they reported the mean meridional wind in the low latitude mesosphere to be up to $40 \mathrm{~m} \mathrm{~s}^{-1}$. Unfortunately, we have no information about zonal wind (which is in general larger than the meridional one and can reach $70 \mathrm{~m} \mathrm{~s}^{-1}$ according to Fig. 7 of Kishore Kumar et al.) that does not allow us to correct the spectral width for actual beam broadening. However, assuming the highest val-
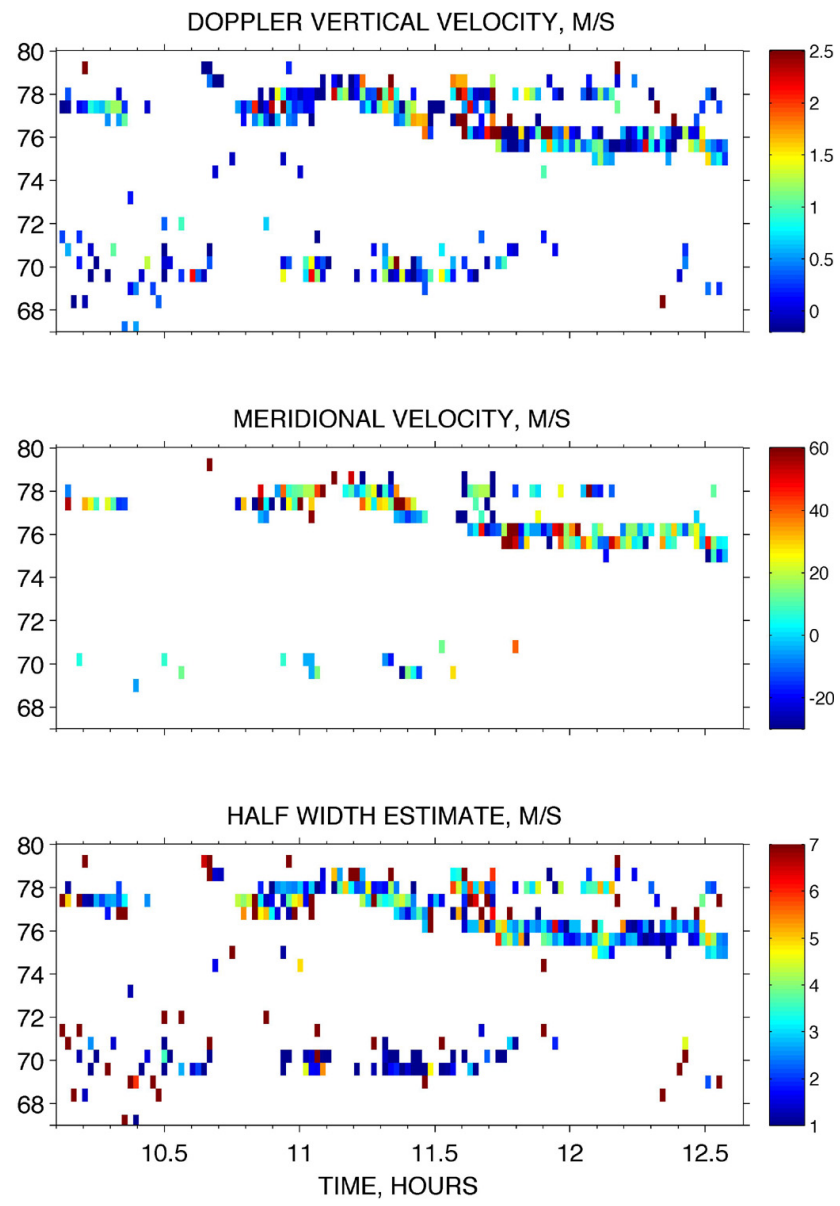

Fig. 6. Doppler vertical (upper panel) and meridional (middle panel) velocity and half spectral width for the vertical beam (lower panel) for the experiment on 11 April 2009.

ues of the components of the horizontal wind, we find beam broadening of at most $1.7 \mathrm{~m} \mathrm{~s}^{-1}$ due to the relatively narrow beam width of $3^{\circ}$ for the Gadanki radar. This value can be considered as the maximum possible beam broadening and we will take it into account in the next section.

\section{Discussion}

Traditionally, radar-echo layers in the mesosphere, both in winter and summer, have been considered to be of turbulent origin. Thus, fluctuating turbulent velocities have been estimated from the spectral widths as described by Hocking (1985). Following the equations in this paper, one can find a relationship between half spectral width $w_{\text {turb }}$ expressed in velocity units, r.m.s. velocity fluctuations $\mathrm{V}$, and turbulent dissipation rate $\varepsilon$ :

$w_{\text {turb }}^{2}=2 \ln 2 \cdot V^{2} \approx 1.4 \cdot \frac{1}{C} \cdot \frac{\varepsilon}{\Omega} \approx 2.9 \cdot \frac{\varepsilon}{\Omega}$, 


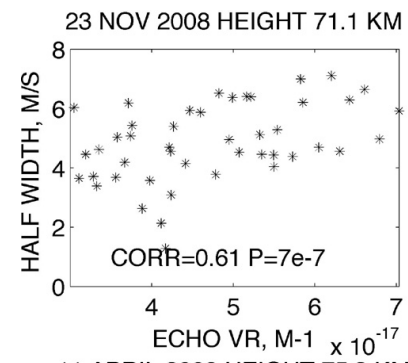

11 APRIL 2009 HEIGHT $75.3 \mathrm{KM}$
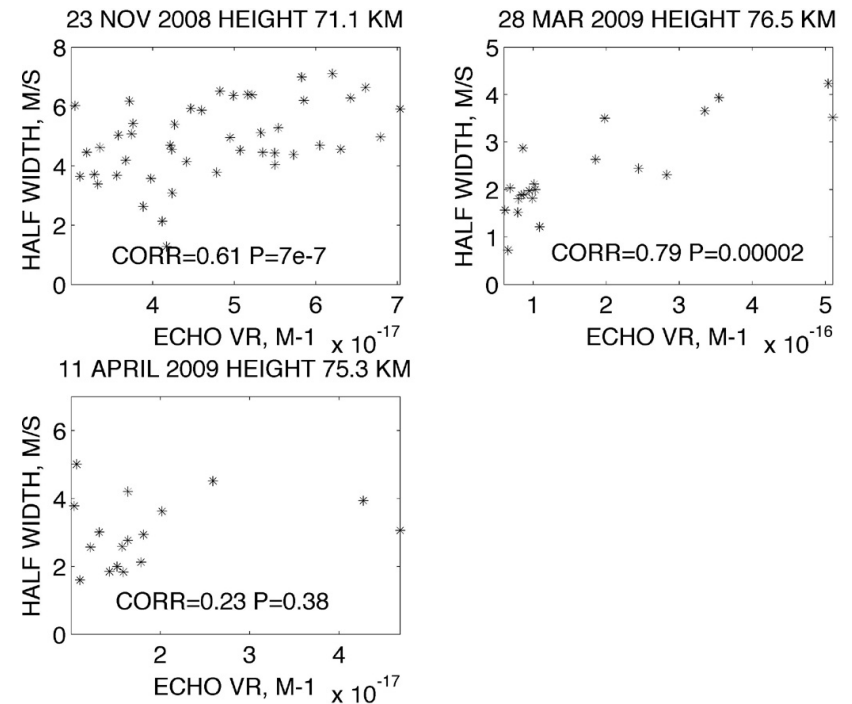

Fig. 7. Scatter plots of the half spectral width versus echo volume reflectivity at selected heights for each of three experiments indicated at the top. Value of correlation coefficient CORR and probability $P$ for testing the hypothesis of no correlation are indicated for each scatter plot. $P$ is the probability of getting a correlation as large as the observed value by random chance, when the true correlation is zero.

where we have used $C=0.49$ (Weinstock, 1981; Hocking, $1996)$ and $\Omega$ is the buoyancy angular frequency.

We have calculated $w_{\text {turb }}$, assuming $\varepsilon$ to be constant for the $60-80 \mathrm{~km}$ altitude range and equal to $0.001 \mathrm{~W} \mathrm{~kg}^{-1}$, $0.01 \mathrm{~W} \mathrm{~kg}^{-1}, 0.1 \mathrm{~W} \mathrm{~kg}^{-1}$ or $0.4 \mathrm{~W} \mathrm{~kg}^{-1}$. $\Omega$ was calculated using the MSISE-90 model (Hedin, 1991) for Gadanki. Altitude profiles of modelled turbulent spectral widths are shown in Fig. 8. Spectral widths are in the range from $1 \mathrm{~m} \mathrm{~s}^{-1}$ to $8 \mathrm{~m} \mathrm{~s}^{-1}$ and have a tendency to decrease slightly with height.

We have computed median spectral widths at selected heights for three experiments without and with correction on maximum beam broadening of $1.7 \mathrm{~m} \mathrm{~s}^{-1}$ as discussed in Sect. 5. They are also shown in Fig. 8. LLME median spectral widths are estimated to range between about 3 and $6 \mathrm{~m} \mathrm{~s}^{-1}$ ( 0 and $5 \mathrm{~m} \mathrm{~s}^{-1}$ with correction) and show a decreasing trend with height. (However, these measurements were done at different circumstances, e.g. seasons, and thus this statement requires further confirmation by more experiments.) If interpreted as turbulent echoes, they correspond to 20$200 \mathrm{~mW} \mathrm{~kg}^{-1}$ turbulent energy dissipation rates. Chandra et al. (2008) and Uma Das et al. (2009) reported energy dissipation rates of $1-100 \mathrm{~mW} \mathrm{~kg}^{-1}$ for the same altitude range, which were derived from the rocket measurements from Sriharikota located about 100 east of Gadanki. The LLME spectral widths for our three cases are close to those $\left(2-3 \mathrm{~m} \mathrm{~s}^{-1}\right)$ measured by Chandra et al. (2008) with the same radar in July 2004. At Jicamarca, Peru, spectral measurements of mesospheric echoes for 37 days made with a 50-MHz MST radar gave mean values of turbulent energy dissipation rates

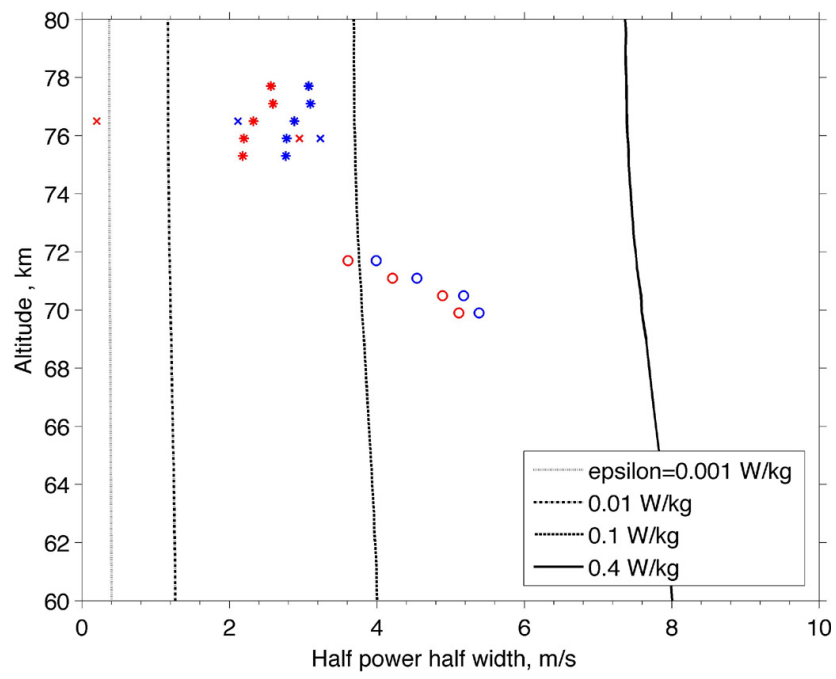

Fig. 8. Profiles of modelled half-power half spectral widths for turbulent scatter with different dissipation rates $\varepsilon$ shown in the text box. Median spectral widths of LLME for three experiments with (red) and without (blue) correction for maximum beam broadening of $1.7 \mathrm{~m} \mathrm{~s}^{-1}$ are shown by symbols: o corresponds to 23 November 2008; $x$ to 28 March 2009 and * to 11 April 2009.

of $5-30 \mathrm{~mW} \mathrm{~kg}^{-1}$ for altitudes between 67 and $80 \mathrm{~km}$ (Guo et al., 2007). However, on some occasions turbulent velocity reached $4 \mathrm{~m} \mathrm{~s}^{-1}$ or more (Fig. 3 in Guo et al., 2007) which corresponds to $\varepsilon$ of $100 \mathrm{~mW} \mathrm{~kg}^{-1}$ or higher. If we compare LLME reflectivities then they range from $10^{-18}$ to $10^{-16} \mathrm{~m}^{-1}$ for Jicamarca (Lehmacher et al., 2009) and from $10^{-17}$ to $10^{-15} \mathrm{~m}^{-1}$ for Gadanki. The radar at Gadanki is less sensitive than that at Jicamarca which explains difference in the lower limits of the reflectivities. We selected for the analysis, the strongest echoes and we see that maximum echo strength is 1 order of magnitude larger at Gadanki than those reported from Jicamarca.

Let us make a comparison between the two sites more accurately. From Eqs. (29) and (38') by Hocking (1985) for isotropic turbulent echoes, one can find an expression for the turbulent dissipation rate $\varepsilon$ :

$\varepsilon \propto\left(\frac{\lambda^{1 / 6} \cdot \Omega \cdot \eta^{1 / 2}}{F^{1 / 2} \cdot M_{\mathrm{e}}}\right)^{3}$,

where $\lambda$ is the radar wave length, $\eta$ is the echo volume reflectivity, $F$ is the filling factor and $M_{\mathrm{e}}$ is the generalized potential refractive index gradient for the mesosphere. With an assumption that $\lambda, \Omega, F, M_{\mathrm{e}}$ are about the same at both sites, for the measured volume reflectivities, one should get turbulent energy dissipation rates for Gadanki 30 times larger than those for Jicamarca. However, from the mean spectral widths, we might explain the difference in dissipation rates up to 7 times. However, $M_{\mathrm{e}}$ depends on both electron density and its vertical gradient, and may differ significantly between Jicamarca and Gadanki at the times of the particular 
experiments which may account for this discrepancy. Beside of this, estimations of highest volume reflectivities for both sites were based on poor statistics. Bearing in mind this fact and the uncertainties in the radar calibrations, the real difference in LLME strengths between Gadanki and Jicamarca might not be so large.

In the experiments in March and April of 2009 when the vertical and $3^{\circ}$ tilted radar beams were used, we found that in most cases echo strength is about the same for the both beams. This non-aspect sensitive scatter is a signature of isotropic turbulence. However, e.g. on 28 March 2009 at 16:05-16:10 UT, backscattered power for tilted beam is about 10 times higher than that for vertical beam. Kumar et al. (2007) reported that although for the majority of mesospheric echoes, the ratio of SNR in the vertical and offvertical beams is close to 1 , it can vary from 0.75 to 1.24 at certain altitude ranges during intervals from 2 weeks up to 2 months indicating tilted scattering layers or/and aspect sensitive scatter.

One more argument supporting turbulence origin of LLME for our three experiments is the relation between the echo strength and spectral width revealed in Fig. 7. Stronger echoes there have broader spectra, with correlation coefficient reaching 0.79 at one height for the experiment in March 2009. For other heights and experiments the statistically significant correlations are always positive although not as strong (not shown). This result is in line of that for LLME at Jicamarca (Sheth et al., 2006) where positive correlation was found for the majority of strong echo layers.

\section{Summary}

We have studied 3 cases of observations of mesospheric echoes, with $600 \mathrm{~m}$ altitude resolution, using the Indian MST radar. For the first time, the radar volume reflectivities for mesospheric echoes over Gadanki were estimated. They are in the range from $10^{-17}$ to $10^{-15} \mathrm{~m}^{-1}$ so that the strongest LLME are stronger at Gadanki than reported for LLME at Jicamarca, Peru by Lehmacher et al. (2009). This may be due partly to stronger turbulence, partly to higher electron density and electron density gradients in Gadanki during these events. In order to draw a final conclusion on echo strength at these two sites, more experiments and better statistics are needed. Echo spectral widths were estimated to vary from 1 to $7 \mathrm{~m} \mathrm{~s}^{-1}$, with median values of $4-6 \mathrm{~m} \mathrm{~s}^{-1}$ at $69-72 \mathrm{~km}$ and of $2-4 \mathrm{~m} \mathrm{~s}^{-1}$ at $73-78 \mathrm{~km}$. Spectral width behaviour with altitude and positive correlations with echo strength are typical for isotropic turbulent echoes observed in the mesosphere at low latitudes in previous studies.

Acknowledgements. This research has been partly funded by the Swedish Research Council under grants 621-2007-4812 and 6212010-3218, Swedish Development Agency SIDA-Swedish Research Links under grant 348-2006-5850.
Topical Editor C. Jacobi thanks two anonymous referees for their help in evaluating this paper.

\section{References}

Berger, U. and von Zahn, U.: Three-dimensional modelling of the trajectories of visible noctilucent cloud particles: An indication of particle nucleation well below the mesopause, J. Geophys. Res., 112, D16204, doi:10.1029/2006JD008106, 2007.

Bremer, J., Hoffmann, P., Höffner, J., Latteck, R., Singer, W., Zecha, M., and Zeller, O.: Long-term changes of mesospheric summer echoes at polar and middle latitudes, J. Atmos. Solar Terr. Phys., 68, 1940-1951, doi:10.1016/j.jastp.2006.02.012, 2006.

Chandra, H., Sinha, H. S. S., Das, U., Misra, R. N., Das, S. R., Datta, J., Chakravarty, S. C., Patra, A. K., Venkateswara Rao, N., and Narayana Rao, D.: First mesospheric turbulence study using coordinated rocket and MST radar measurements over Indian low latitude region, Ann. Geophys., 26, 2725-2738, doi:10.5194/angeo-26-2725-2008, 2008.

Czechowsky, P., Rüster, R., and Schmidt, G.: Variations of mesospheric structures in different seasons, Geophys. Res. Lett., 6, 459-462, 1979.

Ecklund, W. L. and Balsley, B. B.: Long-term observations of the arctic mesosphere with the MST radar at Poker Flat, Alaska, J. Geophys. Res., 86, 7775-7780, 1981.

Fukao, S., Yamanaka, M. D., Ao, N., Hocking, W. K., Sato, T., Yamamoto, M., Nakamura, T., Tsuda, T., and Kato, S.: Seasonal variability of vertical eddy diffusivity in the middle atmosphere, 1. Three-year observations by the Middle and Upper atmosphere radar, J. Geophys. Res., 99, 18973-18987, 1994.

Guo, L., Lehmacher, G. A., Kudeki, E., Akgiray, A., Sheth, R., and Chau, J. L.: Turbulent kinetic energy dissipation rates and eddy diffusivities in the tropical mesosphere using Jicamarca radar data, Adv. Space Res., 40, 744-750, doi:10.1016/j.asr.2007.05.068, 2007.

Hedin, A. E.: Extension of the MSIS Thermospheric Model into the Middle and Lower Atmosphere, J. Geophys. Res., 96, 1159$1172,1991$.

Hocking, W. K.: Measurement of turbulent energy dissipation rates in the middle atmosphere by radar techniques, Radio Sci., 20, 1403-1422, 1985.

Hocking, W. K.: An assessment of the capabilities and limitations of radars in measurements of upper atmosphere turbulence, J. Adv. Space Res., 17, 1137-1147, 1996.

Kirkwood, S., Barabash, V., Belova, E., Nilsson, H., Rao, N., Stebel, K., Osepian, A., and Chilson, P. B.: Polar Mesosphere Winter Echoes during Solar Proton Events, Advances in Polar Upper Atmosphere Research, 16, 111-125, 2002.

Kirkwood, S., Chilson, P., Belova, E., Dalin, P., Häggström, I., Rietveld, M., and Singer, W.: Infrasound - the cause of strong Polar Mesosphere Winter Echoes?, Ann. Geophys., 24, 475-491, doi:10.5194/angeo-24-475-2006, 2006.

Kirkwood, S., Wolf, I., Nilsson, H., Dalin, P., Mikhaylova, D., and Belova, E.: Polar mesosphere summer echoes at Wasa, Antarctica $\left(73^{\circ} \mathrm{S}\right)$ : First observations and comparison with $68^{\circ} \mathrm{N}$, Geophys. Res. Lett., 34, L15803, doi:10.1029/2007GL030516, 2007.

Kirkwood, S., Belova, E., Satheesan, K., Narayana Rao, T., Rajendra Prasad, T., and Satheesh Kumar, S.: Fresnel scatter revisited - comparison of $50 \mathrm{MHz}$ radar and radiosondes in the Arc- 
tic, the Tropics and Antarctica, Ann. Geophys., 28, 1993-2005, doi:10.5194/angeo-28-1993-2010, 2010.

Kubo, K., Sugiyama, K., Nakamura, T., and Fukao, S.: Seasonal and inter annual variability of mesospheric echoes observed with middle and upper atmosphere radar during 1986-1995, Geophys. Res. Lett., 24, 1211-1214, 1997.

Kishore Kumar, G., Venkat Ratnam, M., Patra, A. K., Jagannadha Rao, V. V. M., Vijaya Bhaskar Rao, S., Kishore Kumar, K., Gurubaran, S., Ramkumar, G., and Narayana Rao, D.: Low-latitude mesospheric mean winds observed by Gadanki mesosphere-stratosphere-troposphere (MST) radar and comparison with rocket, High Resolution Doppler Imager (HRDI), and MF radar measurements and HWM93, J. Geophys. Res., 113, D19117, doi:10.1029/2008JD009862, 2008.

Kumar, G. K., Ratnam, M. V., Patra, A. K., Rao, V. V. M. J., Rao, S. V. B., and Rao, D. N.: Climatology of low latitude mesospheric echo characteristics observed by Indian mesosphere, stratosphere, and troposphere radar, J. Geophys. Res., 112, D06109, doi:10.1029/2006JD007609, 2007.

Lehmacher, G. A., Guo, L., Kudeki, E., and Chau, J.: High resolution observations of mesospheric layers with the Jicamarca VHF radar, J. Adv. Space Res., 40, 734-743, 2007.

Lehmacher, G. A., Kudeki, E., Akgiray, A., Guo, L., Reyes, P., and Chau, J.: Radar cross sections for mesospheric echoes at Jicamarca, Ann. Geophys., 27, 2675-2684, doi:10.5194/angeo-272675-2009, 2009.

Lübken, F.-J., Strelnikov, B., Rapp, M., Singer, W., Latteck, R., Brattli, A., Hoppe, U.-P., and Friedrich, M.: The thermal and dynamical state of the atmosphere during polar mesosphere winter echoes, Atmos. Chem. Phys., 6, 13-24, doi:10.5194/acp-6-132006, 2006.

Morris, R. J., Murphy, D. J., Reid, I. M., Holdsworth, D. A., and Vincent, R. A.: First polar mesosphere summer echoes observed at Davis, Antarctica (68.6 ${ }^{\circ}$ S), Geophys. Res. Lett., 31, L16111, doi:10.1029/2004GL020352, 2004.

Narayana Rao, D., Ratnam, M. V., Rao, T. N., and Rao, S. V. B.: Seasonal variation of vertical eddy diffusivity in the troposphere, lower stratosphere and mesosphere over a tropical station, Ann. Geophys., 19, 975-984, doi:10.5194/angeo-19-975-2001, 2001.

Rao, P. B., Jain, A. R., Kishore, P., Balamuralidhar, P., Damle, S. H., and Viswanathan, G.: Indian MST radar 1. System description and sample vector wind measurements in ST mode, Radio Sci., 30, 1125-1138, doi:10.1029/95RS00787, 1995.
Rapp, M. and Lübken, F.-J.: Polar mesosphere summer echoes (PMSE): Review of observations and current understanding, Atmos. Chem. Phys., 4, 2601-2633, doi:10.5194/acp-4-2601-2004, 2004.

Reid, I. M.: Radar observations of stratified layers in the mesosphere and lower thermosphere $(50-100 \mathrm{~km})$, Adv. Space Res., 10, 7-19, 1990.

Sheth, R., Kudeki, E., Lehmacher, G., Sarango, M., Woodman, R., Chau, J., Guo, L., and Reyes, P.: A high-resolution study of mesospheric fine structure with the Jicamarca MST radar, Ann. Geophys., 24, 1281-1293, doi:10.5194/angeo-24-12812006, 2006.

Smirnova, M., Belova, E., Kirkwood, S., and Mitchell, N.: Polar mesosphere summer echoes with ESRAD, Kiruna, Sweden: Variations and trends over 1997-2008, J. Atmos. Solar-Terr. Phys., 72, 435-447, doi:10.1016/j.jastp.2009.12.014, 2010.

Stebel, K., Blum, U., Fricke, K.-H., Kirkwood, S., Mitchell, N. J., and Osepian, A.: Joint radar/lidar observations of possible aerosol layers in the winter mesosphere, J. Atmos. Solar Terr. Phys., 66, 957-970, 2004.

Swarnalingam, N., Hocking, W. K., and Argall, P. S.: Radar efficiency and the calculation of decade-long PMSE backscatter cross-section for the Resolute Bay VHF radar, Ann. Geophys. 27, 1643-1656, doi:10.5194/angeo-27-1643-2009, 2009.

Uma Das, H. S. S., Sinha, Som Sharma, Chandra, H., Das, Sanat K.: Fine structure of the low-latitude mesospheric turbulence, J. Geophys. Res., 114, D10111, doi:10.1029/2008JD011307, 2009.

Weinstock, J.: Using radar to estimate dissipation rates in thin layers of turbulence, Radio Sci., 16, 1401-1406, 1981.

Woodman, R. F. and Guillen, A.: Radar observations of winds and turbulence in the stratosphere and mesosphere, J. Atmos. Sci., 31, 493-503, 1974.

Zecha, M., Bremer, J., Latteck, R., Singer, W., and Hoffmann, P.: Properties of midlatitude mesosphere summer echoes after three seasons of VHF radar observations at 54 N, J. Geophys. Res., 108, 8439, doi:10.1029/2002JD002442, 2003.

Zeller, O., Hoffmann, P., Bremer, J., and Singer, W.: Mesosphere summer echoes, temperature, and meridional wind variations at mid- and polar latitudes, Atmos. Solar Terr. Phys., 71, 931-942, doi:10.1016/j.jastp.2009.03.013, 2009. 